\title{
Analysis of Nasal Airway Resistance in Normal Healthy Adult Population of Raipur in Chhattisgarh by Rhinomanometry
}

\author{
Shailendra Guptaํ, Anupam Minj², Vidyabhushan ${ }^{3}$ \\ ${ }^{1}$ Assistant Professor, Department of Otorhinolaryngology (ENT), GMC, Ambikapur, Chhattisgarh, India. \\ ${ }^{2}$ Senior Resident, Department of Otorhinolaryngology (ENT), GMC, Ambikapur, Chhattisgarh, India. \\ ${ }^{3}$ Asssitant Professor, Department of Otorhinolaryngology (ENT), CIMS, Bilaspur, Chhattisgarh, India.
}

\section{ABSTRACT}

\section{BACKGROUND}

Nasal resistance plays an important role, in governing normal nasal breathing as well as in total airway resistance. Active anterior rhinomanometry procedure is reliable, easily reproducible technique to measure nasal airway resistance. When recommending measurement of nasal air flow resistance, the anterior active rhino manometry (AARM) is strongly considered as a satisfying candidate for a "gold standard" of assessment. However, few studies have published normal values of airway resistance in Asians. The aim of present study was to measure normal total nasal resistance (NR) values in normal adult population of Raipur city in Chhattisgarh state.

\section{METHODS}

All participants were selected from healthy adult population of Chhattisgarh based on purposive sampling. Participants were selected from both sexes and the age was between 15 to 40 years. Among the 114 cases, 58 were males and 56 were females. All the cases where free from nasal complaints and also had no systemic diseases for the last six months. Active anterior rhinomanometry examination was done in upright position with closed mouth during spontaneous respiration. Trans-nasal airflow was recorded at 150 Pa pressure by Rhinomanometer. The measurement results were displayed in real time and after the test was completed, data was obtained in the form of printed graph. Calculation of total nasal airflow resistance (NAR) was calculated as per Ohms law.

\section{RESULTS}

The mean values for the sum of the resistance of right and left nasal cavity was 0.23 $\mathrm{Pa} / \mathrm{cm}^{3} / \mathrm{S}$ with maximum measurement was $0.35 \mathrm{~Pa} / \mathrm{cm}^{3} / \mathrm{S}$ and Minimum 0.15 $\mathrm{Pa} / \mathrm{cm}^{3} / \mathrm{S}$ was noted in $75.43 \%$ in present study population. Age and sex factor had a non-significant effect in the results ( $\mathrm{p}$ values less than 0.01 ).

\section{CONCLUSIONS}

This study reports normal range and mean value of total nasal airway resistance for the healthy adult population of Raipur city in Chhattisgarh state. Sex and age wise factors do not have a statistically significant effect on the total nasal airway resistance in healthy adult population.

\section{KEY WORDS}

Normal Adult Population, Nasal Airway Resistance (NAR), Active Anterior Rhinomanometry (AARM)

\author{
Corresponding Author: \\ Dr. Shailendra Gupta, \\ M. G. Road, Ambikapur-497001, \\ Chhattisgarh, India. \\ E-mail:imaambikapur@gmail.com
}

DOI: $10.14260 / j e m d s / 2019 / 551$

Financial or Other Competing Interests: None.

How to Cite This Article:

Gupta S, Minj A, Vidyabhushan. Analysis of nasal airway resistance in normal healthy adult population of Raipur in Chhattisgarh by rhinomanometry. J. Evolution Med. Dent. Sci. 2019;8(32):2530-2533, DOI: $10.14260 / j e m d s / 2019 / 551$

Submission 14-05-2019, Peer Review 26-07-2019, Acceptance 02-08-2019, Published 12-08-2019. 


\section{BACKGROUND}

The nose acts as a passageway for airflow. Nasal airway resistance accounts for more than half of total airway resistance[1] and plays an important role in nasal breathing. Nasal airflow always occurs along a pressure gradient from a high-pressure area to a low-pressure area of the airway. During normal breathing, the expansion of the lungs on inspiration moves air through the nose into the lungs while on expiration, the respiratory muscles relax and the elastic lungs recoil to create a pressure in the lungs that is greater than the atmospheric pressure at the nostrils.

The nasal septum divides the nose into the two cavities and is composed of a bony and a cartilaginous framework. Anatomical aspects of the nasal airway consist of 3 parts. The upper third includes the paired nasal bones. The middle third is composed by cartilages framework fused to the septal cartilage in the midline. The lower third of the nose have softer lower lateral cartilages. From a functional standpoint, the nasal cavity can also be divided into three areas. The nasal valve plays an important role in nasal airway resistance of the lower and middle thirds of the nose. The vestibule contributes to about one-third of the airway resistance, and acts as the flow-limiting segment of inspiration. The valve region contributes to most of the remaining two-thirds of the resistance.

Nasal resistance is primarily influenced by the sympathetic system, which determines the state of engorgement of the capacitance vessels in the venous erectile tissue on the inferior and middle turbinate mucosa and the septum. Nasal obstruction is a common symptom in the general population. ${ }^{[2]}$ Complaint of blocked nose is a complex clinical problem, frequently difficult to assess. It is defined as discomfort manifested as a feeling of insufficient airflow through the nose. The nose is a complicated airway with constrictions and changes in airflow direction. The sensation of obstruction of airflow through the nose may be one of the most distressing of all symptoms of nasal disease. The degree to which nasal obstruction causes symptoms is determined not only by the severity of the obstruction but also by the subjective perception of obstruction to nasal airflow. So, it is important to be able to accurately assess the normal values of nasal airflow resistance.

The perception of nasal airflow or feelings of obstruction is subjective information. Here prominence is not given to the facts but patient's interpretation and personnel opinion. It is important to note that subjective is not subjected to verification unlike in case of objective. This is simply because subjective reflects the standpoint by means of patients view only and also the study of subjective perception of nasal airflow cannot be used to assist the clinician to diagnose and treat nasal complaints as well as quantification for further research. Various methods are used to improve our ability to judge objectively measurement of nasal airway and resistance include rhinomanometry and acoustic rhinometry. These two methods provide complementary and important objective information concerning the nasal airway. In general, rhinomanometry provides information about nasal airway flow and resistance, while acoustic rhinometry shows the anatomic cross-sectional area, the geometry of the nasal cavity.
Rhinomanometry is a gold standard and widely accepted method which provides a functional measure of nasal airflow resistance or conductance. It is a quantifiable, reproducible objective test with strong correlation to the subjective perception of nasal airflow. We followed the same technique, the anterior active rhino manometry (AARM) for assessment of total nasal airway resistance.

Aim of present study was to evaluate normal range of total nasal airway resistance in healthy adult population of Raipur City in Chhattisgarh state. We did this study in department of Otorhinolaryngology, pt. J. N. M Medical College Raipur, Chhattisgarh over 114 subjects. These subjects were no nasal as well as systemic diseases for last 6 month. Participants were selected from both sex and different age groups between 15 to 40 years.

\section{METHODS}

This study was done at the department of Otorhinolaryngology, pt. J. N. M. Medical College Raipur in Chhattisgarh, over 114 subjects. Ethical committee of the medical institution approved this study. Among the 114 Study subjects, 58 were males and 56 were females. The participants were selected based on purposive sampling. Written consent was taken by all participants before the procedure. All the subjects were free from nasal diseases as well as systemic diseases for last 6 months. None of these participants were using any oral or injectable medicine affecting systemic or nasal circulation. A proper Otorhinolaryngological examination of all subjects was performed, which showed normal findings. Participants, who were taking medication or having nasal diseases, were not included in study as it may cause change in total nasal airway resistance in same condition. Subject below the age of 15 years or above the 40 years were also not included as the aim of present study was to decide the total nasal airway resistance in adult healthy population only. All the participants were distributed according to the age and sex.

Active anterior rhinomanometry is recognised as a standard procedure for evaluating the objective assessment of total nasal airflow resistance. Same procedure was also used in present study. All subjects were acclimatized in the laboratory environment for 30 minutes. The active anterior rhinomanometry procedure was explained to all participants. Series of trial examinations were done with intention to eliminating any anxiety which is a main factor for reducing nasal airway resistance.

The goal of rhinomanometry was to determine the airflow that could pass through the nose at a given pressure. There are two occasions when anterior active rhinomanometry is not possible to use-

1. The nasal cavity that transmits the pressure from the nasopharynx is totally obstructed no measurement is possible.

2. In septal perforation the flows and pressures recorded are not representative of the nasal Cavity being studied.

Rhinomanometer used for active anterior rhinomanometry had following features. During quiet breathing Trans nasal pressure differences and nasal airflow both were recorded in the same time. Trans nasal Pressure and 
airflow curve was demonstrated in a visual display unit (VDU) which assured controlling the regularity of subjects breathing.

Trans nasal airflow was recorded in form of printed graph. During the transition from graphical to computerized rhinomanometry it became apparent that the most important parameter was neither the pressure nor the airflow velocity, but the relation between these two parameters. This allowed us to better describe the physics of the nasal air stream. The basis of these relations became the accepted standard for evaluating the normal values of total nasal resistance. In this study, active anterior rhinomanometry; the measurement was done during spontaneous Breathing with the patient in a sitting position.

An airtight mask is fitted over the nose and connected to a pneumotachograph to measure flow through the side to be tested. A tube was sealed to the nostril of the opposite side to measure the pressure gradient between the nostril and the nasopharynx of the tested side. This was a dynamic test that studied nasal ventilation and showed the nature of the air stream. Pressure was recorded in one nostril while the patient breathes through the other. Rhinomanometry measured the pressure difference $(\Delta \mathrm{p})$ and airflow $\left(\mathrm{V}^{\circ}\right)$ between the posterior and the anterior of the nose during inspiration and expiration. Nasal resistance was calculated according toOhm's law $\left(\mathrm{R}=\Delta \mathrm{P} / \mathrm{V}^{\circ}\right)$

Nasal airway resistance $=$ pressure across the nose $/$ the nasal airflow

\section{$\left(\mathrm{R}=\Delta \mathrm{P} / \mathrm{V}^{\circ}\right)$}

The nasal pressures were measured in Pascal (Pa). The Pascal is a standard international unit (S.I). V, total trans nasal airflow (Sum of right and left side of nasal cavity) was measured in units of cubic centimetres per second $\left(\mathrm{cm}^{3} / \mathrm{sec}\right)$. The units of nasal resistance were expressed as a combination of pressure and flow calculated from the formula above and were expressed as Pascal per cubic centimetres per second $\left(\mathrm{Pa} / \mathrm{cm}^{3} / \mathrm{sec}\right)$. During quiet breathing at low pressures and flows the relationship between pressure and flow is almost a straight line. But the relationship between nasal pressure and flow is disturbed at higher pressures it means that the relationship between pressure and flow were not constant but differed according to where on the pressure flow curve, the resistance was measured. Tran's nasal pressure was kept static in $150 \mathrm{~Pa}$ in this study because at this pressure nasal airflow can be assessed with minimal physical effort and ensuring maximal air conditioning with efficient warming and humidification of the air, as it passed through the nose to the lungs.

\section{Statistical Analysis}

The total trans nasal airway resistances were recorded as mean standard deviation. TNRs of different age groups were analysed according to gender. All tests were having P values less than 0.05 and were concluded statistically significant.

\section{RESULTS}

The present study demonstrated that the mean value of total nasal airway resistance was $0.23 \mathrm{~Pa} / \mathrm{cm}^{3} / \mathrm{s}$ at 150 Pascal pressure. However, the range of total nasal airflow resistance was from 0.15 to $0.35 \mathrm{~Pa} / \mathrm{cm}^{3} / \mathrm{s}$ at the same pressure. The mean values for the sum of the resistance of right and left nasal cavity was $0.23 \mathrm{~Pa} / \mathrm{cm}^{3} / \mathrm{S}$ with maximum measurement was $0.35 \mathrm{~Pa} / \mathrm{cm}^{3} / \mathrm{S}$ and Minimum $0.15 \mathrm{~Pa} / \mathrm{cm}^{3} / \mathrm{S}$ was noted in $75.43 \%$ in present study population (Table $1 \&$ Graph)Age and Sex factors had a non-significant effect in results (P values less than 0.01 )

\begin{tabular}{|c|c|c|c|c|c|c|}
\hline $\begin{array}{l}\text { Total Nasal Resistance } \\
{\left[\mathrm{Pa} / \mathrm{cm}^{3} / \mathrm{s}\right] \text { at } 150 \mathrm{~Pa}}\end{array}$ & \multicolumn{2}{|c|}{$(0.14-0.24)$} & \multicolumn{2}{|c|}{$(0.25-0.35)$} & \multicolumn{2}{|c|}{$(0.36-0.38)$} \\
\hline Age Group & Male & Female & Male & Female & Male & Female \\
\hline $16-20$ & 10 & 11 & 01 & 02 & 00 & 00 \\
\hline $21-25$ & 13 & 08 & 01 & 03 & 00 & 01 \\
\hline $26-30$ & 05 & 09 & 03 & 01 & 00 & 00 \\
\hline $31-35$ & 11 & 08 & 02 & 04 & 02 & 00 \\
\hline $36-40$ & 06 & 06 & 04 & 02 & 01 & 01 \\
\hline Total & 44 & 42 & 11 & 12 & 03 & 02 \\
\hline$\%$ & \multicolumn{2}{|c|}{$75.43 \%$} & \multicolumn{2}{|c|}{$20.18 \%$} & \multicolumn{2}{|c|}{$4.39 \%$} \\
\hline
\end{tabular}

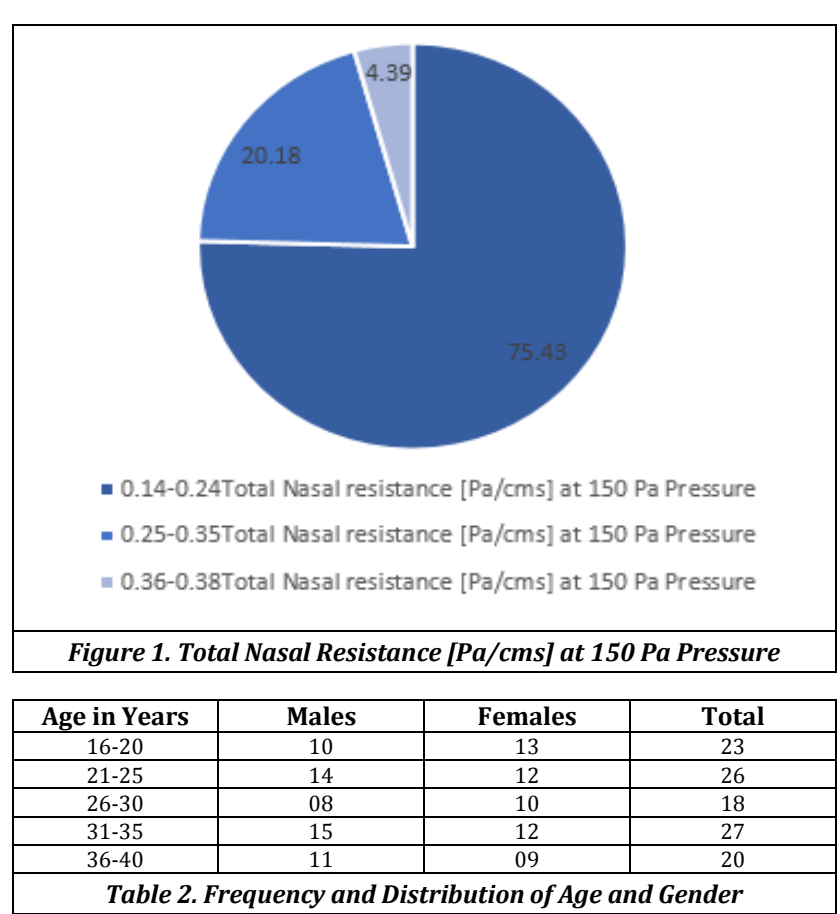

\section{DISCUSSION}

The first attempt at objectively measure nasal airflow was probably done by Zwaardemaker in 1889.[3] He placed a cold mirror beneath the nose and observed the size of the resultant condensation spots. Kayser was started scientific studies on nasal airflow in 1895 and advocated for objective measurement of nasal airflow.[4] In 1901, Glatzel,[5] modified Zwaardemakers hygrometric method by using a metal plate instead of a mirror. There was no deformation of the nostrils, and no artificial airstream was used but they were dependent on environmental factors such as temperature and humidity etc.

So, these methods were accepted as physiologically perfect but, not recognised in clinical use. Further modifications of hygrometric methods were demonstrated by Jochims in 1938 by the fixation of the condensed pattern with Gummi Arabicum. ${ }^{6}{ }^{6}$ Later these methods were replaced by physics and general fluid dynamics; Methods of estimation were 
replaced by measurements and calculations. Thus, rhinology as well as pneumology was following methods based on physical parameters of flow and pressure. In 1958 the first rhinomanometric procedure was introduced. But it was passive types and difficult for patients to hold their breath and not to swallow when air was being blown through their nose. Sometimes they have even needed general anaesthesia. These methods have not accepted clinically.

Active rhinomanometry can be anterior with the pressure measured at the nostrils or posterior with the pressure measured in the nasopharynx at the base of the tongue. These methods were first used for research purposes since then, numerous and important developments have been made like the flow regulator. Kern started the standardization procedure for Rhinomanometry.[7]

In 1984, The International Standardization Committee of Rhinomanometry (ISCR) lead by Clement from Belgium published first report regarding standardization procedure of Rhinomanometry.[8] Committee accepted that AAR was the most common and the most physiological technique of rhinomanometry. In 2005, A final report from ISCR came that resolved all the controversies related to Rhinomanometry procedure and achieved a mutual understanding of clinicians, surgeons, scientists and manufacturers now it is widely used for routine clinical cases.[9]

Aerodynamics of nose is affected by two factors one is rigid component and other are variable which effect normal function of human nose. Rigid components include osseous and cartilaginous framework of nose. Comparisons to the static components, variable components are mainly influenced by physiological condition of nasal mucosa, physical exercise, hormonal stimuli, environment temperature, humidity and nasal cycle. Total nasal airway resistance reflects an overall measure of the resistance of both sides of nasal cavity. The benefit of measuring the total NAR is to avoid the effect of nasal cycle over unilateral nasal airway resistance. There is a difference in the nasal airway resistance between oriental, Caucasian and Negroid races. These differences were more significant when the total NAR was calculated in decongested nose. This difference was found due to difference in static component of nasal framework that's includes nasal width and ventral and transverse nostril diameter. A study by Ohki et al. In 1991 on healthy population of oriental, Caucasian and Negroid, the mean total NAR was 0.184, 0.129 and 0.146 $\mathrm{Pa} / \mathrm{cm}^{3} / \mathrm{s}$ respectively.[10]

Study by Morris et al. in 1992 on healthy adult subjects demonstrated that the mean total nasal airway resistance was around $0.23 \mathrm{~Pa} / \mathrm{cm}^{3} / \mathrm{s}$ with range from 0.15 to $0.39 .{ }^{[11]}$ And another study of 85 subjects has showed that the mean value of total nasal airway resistance was. $0.24 \mathrm{~Pa} / \mathrm{cm}^{3} / \mathrm{s}$ with range from 0.12 to $0.52 \mathrm{~Pa} / \mathrm{cm}^{3} / \mathrm{s}$ in Malay population. ${ }^{[12]}$ Mean value of total nasal airway resistance was found $0.21 \mathrm{~Pa} / \mathrm{cm}^{3} / \mathrm{s}$ in German population.[13] In our study, factors such as sex and age of the subjects did not have a statistically significant impact on total NAR healthy adult population of Raipur in Chhattisgarh.[14] It was observed that the maximum nasal airway resistance recorded was $0.38 \mathrm{~Pa} / \mathrm{cm}^{3} / \mathrm{s}$, but this can be explained on the basis of static component of nasal Framework differences among individuals as well as environmental pollution in Raipur City habituate high total NAR without producing nasal symptoms. Study suggested that there was strong correlation between subjective sensation of nasal patency and the general resistance of airway.[15]

\section{CONCLUSIONS}

This study reports normal range and mean value of total nasal airway resistance for the healthy adult population of Raipur in Chhattisgarh. Sex and age wise factors do not have a statistically significant impact on the total nasal airway resistance in healthy adult population.

\section{REFERENCES}

[1] Bailey B. Nasal function and evaluation, nasal obstruction. In: Head and Neck Surgery Otolaryngology. $2^{\text {nd }}$ edn. New York, NY: Lippincott Raven 1998: p. 335-44, 376, 380-90.

[2] Jessen M, Malm L. Definition, prevalence and development of nasal obstruction. [Review]. Allergy 1997;52(Suppl 40):3-6.

[3] Zwaardemaker H. Ademmaanslag al diagnosticum der nasal stenoe. Nederlands Tijdschrift Voor Greneskunde 1889;25:297-300.

[4] Kayser R. Die exacte Messung der Luftdurchgängigkeit der Nase. Arch Laryngol 1895;3:101-210.

[5] Glatzel W. Zur Prufung der Luftdurchgängigkeit der Nase. Ther Gegenw 1901;42:348.

[6] Jochims J. Zur Methodik des Glatzelspiegels. Europ J Pediat 1938;60:147-53.

[7] Kern EB. Standardization of rhinomanometry. Rhinology 1977;15(3):115-9.

[8] Clement PA. Committee report on standardization of rhinomanometry. Rhinology 1984;22(3):151-5.

[9] Clement PA, Gordts F, Standardisation Committee on Objective Assessment of the Nasal Airway, et al. Consensus report on acoustic rhinometry and rhinomanometry. Rhinology 2005;43(3):169-79.

[10] Ohki M, Naito K, Cole P. Dimensions and resistances of the human nose: racial differences. Laryngoscope 1991;101(3):276-8.

[11] Morris S, Jawad MS, Eccles R. Relationships between vital capacity, height and nasal airway resistance in asymptomatic volunteers. Rhinology 1992;30(4):259-64.

[12] Suzina AH, Hamzah M, Samsudin AR. Active anterior rhinomanometry analysis in normal adult Malays. J Laryngol Otol 2003;117(8):605-8.

[13] Bermuller C, Kirsche H, Rettinger G, et al. Diagnostic accuracy of peak nasal inspiratory flow and rhinomanometry in functional rhinosurgery. Laryngoscope 2008;118(4):605-10.

[14] Younis F, Duvvi S, Walker T, et al. Sino-nasal assessment questionnaire: a specific outcome measure for rhinosinusitis, but what is the range in the asymptomatic population? J Laryngol Otol 2007;121(7):650-2.

[15] Roithmann R, Cole P, Chapnik J, et al. Acoustic rhinometry, rhinomanometry and the sensation of nasal patency: a correlative study. Journal of Otolaryngology 1994;23(6):454-8. 